\title{
SÓLO ESTA VOZ TAN MUDA: LITERATURA Y LEGALIDAD EN TEXTOS ESCRITOS EN LA CÁRCEL
}

\author{
ONLY THIS MUTE VOICE: LITERATURE AND \\ LEGALITY IN TEXTS WRITTEN IN PRISON
}

Juan Pablo PARCHUC

Universidad de Buenos Aires

jparchuc@filo.uba.ar

\begin{abstract}
Resumen: En este artículo propongo indagar la relación entre literatura y legalidad en textos escritos en la cárcel. Voy a analizar un corpus compuesto por poemas y relatos realizados en contextos de encierro penal durante los últimos diez años en Argentina, focalizando los modos en que la escritura en la cárcel responde a un estado de la lengua y la moral de la ley, para reflexionar sobre los límites de la democracia frente una nueva avanzada del neoliberalismo en América Latina.
\end{abstract}

Palabras clave: teoría; literatura; legalidad; escritura; cárcel

Abstract: In this article I propose to investigate the relationship between literature and legality in texts written in prison. I will analyze a corpus composed of poems and stories written in prison during the last ten years in Argentina, focusing on the ways in which writing in jail responds to a state of the language and the morality of the law, so as to reflect on the limits of democracy in a new advance of neoliberalism in Latin America.

Keywords: theory; literature; legality; writing; prison 
$\mathrm{E}$ n el catálogo introductorio a la exposición Sublevaciones, Georges Didi-Huberman (2017: 22) refiere un estilo de canto inventado en las prisiones españolas de comienzos del siglo veinte: las carceleras. En estos cantos, dice, a menudo todo el horizonte aparece apoyado en el brillo de un cigarro consumiéndose en la oscuridad. De ese pequeño lucero brotan imágenes, recuerdos, penas, anhelos y odios. Y la voz (o el grito) que insiste en la penumbra, se alza y desafía la sumisión, rescatando de las sombras palabras, gestos y acciones que, si bien pueden ser consideradas pequeñas rebeliones, se asocian a otras luchas, revueltas y hasta revoluciones. Los «tiempos oscuros», agrega Didi-Huberman, extendiendo la imagen, no sólo quitan la capacidad de ver más allá, sino que pesan sobre la cabeza; la comprimen hasta ofuscar el deseo y el pensamiento. Para superarlos, apelamos a fuerzas o energías que pueden provenir de muchos lados pero encuentran uno de sus reservorios fundamentales en la memoria de situaciones extremas, aquellas que caminan por ese borde donde se pone en juego la vida y llega a tocarse la muerte; un límite que recorre también, a veces, la literatura.

En este artículo propongo indagar la relación entre literatura y legalidad ${ }^{1}$ en textos escritos en la cárcel. La elección de este material supone un desafío, en tanto se trata de textos poco conocidos y al margen de los circuitos de valoración académica y de mercado. Mi interés en ellos no depende exclusivamente del vínculo con el tema que propongo abordar (la cárcel es el límite inferior del estado de derecho, la expresión más violenta y cruel de la ley), sino que surge del trabajo realizado en el marco de programas y proyectos de enseñanza, investigación y extensión universitaria en contextos de encierro, de los que formo parte desde hace más de doce años ${ }^{2}$. El objetivo de estos proyectos no es sólo estudiar las características, efectos y condiciones de este tipo de escritura, realizada en situaciones de vulneración de derechos humanos y marginación social, sino también promover acciones que intervengan sobre la realidad carcelaria a través de la literatura y otras formas de arte y organización.

Desde esa perspectiva, para seguir los lineamientos de la convocatoria realizada por este dossier de la revista Tropelías, propongo leer un corpus de poemas y relatos escritos en contextos de encierro durante los últimos diez años en Argentina, focalizando el vínculo específico que establecen con sus

${ }^{1}$ El principio jurídico de legalidad supone que los sujetos y poderes públicos están sometidos a las leyes y al derecho, según el enunciado abstracto: «Nadie puede ser obligado a hacer lo que la ley no manda, ni privado de lo que ella no prohíbe». Este principio está asociado con la racionalización del sistema constitucional y penal moderno y, en su funcionamiento, implica un proceso de repetición o citación de la ley que sostiene el carácter de verdad del juicio cuando la narración de un hecho o la descripción de un comportamiento puede enmarcarse en un caso definido por las normas establecidas. En mi investigación recupero operativamente este concepto de legalidad para indagar los límites de lo que se conoce como «estado de derecho», pero también el orden moral que funda, sus cambios y redefiniciones, a partir del análisis de escenas, tramas y sujetos de la ley en la literatura.

${ }^{2}$ El Programa UBAXXII de la Universidad de Buenos Aires, con más de treinta años de trayectoria en educación superior en establecimientos penitenciarios federales (Parchuc et al., 2016, Laferriere 2008); y las iniciativas que fuimos construyendo en ese marco y otros, a partir del año 2005, desde la Facultad de Filosofía y Letras: el Programa de Extensión en Cárceles, el proyecto de investigación UBACYT «Escribir en la cárcel: intervenciones con la literatura y otras formas de arte y organización» y el de extensión universitaria UBANEX «Prácticas y acciones socioeducativas y culturales en contextos de encierro: derechos e inclusión de personas privadas de libertad y liberadas», entre otros. 
condiciones de producción, consideradas no en términos de «contexto», sino como parte del espacio que abre la literatura. Voy a concentrarme en los modos en que la escritura en la cárcel responde a un estado de la lengua y la moral de la ley, remarcando, desplazando y volviendo a trazar los límites de la democracia. En tal sentido, propongo prestar atención a saberes, estrategias y formas de resistencia y organización que atraviesan los textos, para pensar (enfrentar) algunos de los problemas e interrogantes culturales y políticos que produce la nueva avanzada del neoliberalismo hoy en América Latina, encarados desde la teoría y la crítica literaria. Me interesa sobre todo registrar los tonos, matices e inflexiones que articulan esas respuestas.

\section{Los límites de la democracia}

Los cambios económicos y político vividos en la región durante los últimos dos o tres años implicaron una redefinición de las relaciones entre Estado y sociedad civil, en el sentido de una nueva articulación hegemónica que ha permitido profundizar las violencias estructurales propias del capitalismo, tanto en términos materiales como simbólicos. Esos cambios tienen su correlato en la política criminal y de seguridad: el incremento de las desigualdades como consecuencia de la transferencia de ingresos desde las poblaciones más postergadas hacia los sectores concentrados de la economía, a través de un programa económico de corte neoliberal ${ }^{3}$ ha ido acompañado por un reforzamiento del sistema represivo que apunta al control de las poblaciones pobres y a la criminalización y represión de la protesta social. Como parte de estas formas de gobernabilidad del conflicto social y las disputas en el ámbito público generadas por la crisis (real o forjada), las prácticas y discursos del sistema penal han venido articulándose con nuevos reclamos de «ley y orden» que se extienden como un rumor social, amplificando la demanda de «mano dura» y encarcelamiento, según un paradigma que podríamos asociar al de la «tolerancia cero», que ya mostró su fracaso a fines de los noventa y comienzos de dos mil (Daroqui, 2008: 13-14; Wacquant, 2004: 11-17). Por supuesto, no sin desplazamientos y redefiniciones.

Las características sobresalientes de esta política pueden observarse en la saturación policial en las calles y los controles intensivos sobre determinados grupos y sectores considerados «peligrosos» para el orden y la «moral pública», en especial, jóvenes de los barrios periféricos, inmigrantes, vendedores/as ambulantes, personas en situación de calle, manifestantes, piqueteros, mujeres, gays, lesbianas, travestis y personas trans; el encierro penal y las prácticas judiciales de detención preventiva como regla más que excepción, en el caso de las poblaciones más vulnerables; reformas legislativas para aumentar las penas, ampliar la población penalmente responsables (baja de la edad de punibilidad) y reducir las posibilidades de acceso a salidas anticipadas ${ }^{4}$; reordenamiento de las instituciones

\footnotetext{
${ }^{3}$ Basado en la apertura financiera y comercial sin barreras de protección, el ajuste fiscal, política de endeudamiento externo, despidos, flexibilización laboral, recorte de derechos y precarización de las condiciones de vida.

${ }^{4}$ Durante el año 2016, se aprobaron reformas a la ley penal y al régimen de ejecución de la pena que establecieron el aumento de las escalas penales para ciertos delitos y la restricción - de hecho o por efecto de la burocratización del sistema - de la posibilidad de salidas anticipadas: salidas transitorias, régimen de semilibertad, libertad asistida y condicional.
} 
penitenciarias y mayores restricciones del acceso a la salud, la educación y el trabajo intramuros, sumado a un incremento del hacinamiento, la tortura y las multiples violencias vividas en la cárcel ${ }^{5}$. Estas prácticas y dispositivos son acompañados por un renovado discurso de la «defensa de la sociedad», que circula tanto en los tribunales como en los medios de comunicación y las redes sociales, junto con operaciones de pánico moral que van creando un estado de guerra contra cualquier tipo de disidencia o quienes son identificados como factores de conflictividad social (Zaffaroni, 2006: 25-26; Hall et al., 1978). Quienes caen en las redes del poder, son tachados/as de «delincuentes» o enmarcados/as como parte del combate contra la inseguridad y el desorden en la vía pública. Estas operaciones vuelven anónimas y deshumanizan a las personas perseguidas por las fuerzas policiales y son capturadas por los dispositivos penales, al punto de llegar a justificar la represión, el «gatillo fácil» ${ }^{6}$, la tortura y hasta la muerte en cárceles y comisarías.

Desde ya, estos cambios responden a un programa de largo aliento en América Latina, cuyos hilos pueden remontarse y aún hoy anudan lenguajes y afectos con las dictaduras de la segunda mitad del siglo veinte (Cesaroni, 2013: 17-28) y, más allá, con la trama persistente del racismo que ha sostenido la esclavitud y la expropiación desde la época colonial (Segato, 2007: 143-144). Estos hilos se tensan y entrelazan con otros, superponiendo temporalidades y creando nuevas imágenes o figuras que permiten leer, al derecho y al revés, la trama legal o lo que aquí llamamos legalidad: las formas en que se establece y legitima la ley; la moral que funda o sobre la que se monta; el tipo de afectos y sensibilidades que regula; las subjetividades que produce pero también aquellas que niega, separa, deja afuera; los cuerpos que marca, daña o directamente elimina. Los documentos históricos y testimonios de las cárceles argentinas desde el siglo diecinueve hablan de instalaciones vetustas y llenas de personas sin condena, tortura y maltrato sistemáticos, pequeñas y grandes tiranías, abandono, silencios y muerte (Caimari, 2017: 43; Caimari, 2004). En otro lugar, señalamos las similitudes entre los relatos del encierro hoy y la cárcel del pasado, para llamar la atención sobre las deudas y límites de la democracia (Parchuc, 2013: 78-79). No me propongo aquí registrar nuevamente esas similitudes ni constatar sus diferencias, tanto como indicar de qué manera esas tramas atraviesan la lengua, los

\footnotetext{
${ }^{5}$ Véanse los informes del Comité contra la Tortura de la Comisión Provincial por la Memoria, la Procuración Penitenciaria de la Nación y la Procuraduría de Violencia Institucional del Ministerio Público Fiscal. También puede consultarse el Registro Nacional de Casos de Tortura y/o Malos Tratos, que elaboran algunos de estos organismos junto con el Grupo de Estudios sobre Sistema Penal y Derechos Humanos del Instituto Gino Germani de la Facultad de Ciencias Sociales de la Universidad de Buenos Aires.

${ }^{6}$ En nuestro país, se llama «gatillo fácil» al abuso de arma y las ejecuciones ilegales por parte de las fuerzas de seguridad. El nombre proviene de un famoso texto del escritor argentino Rodolfo Walsh: «La secta del gatillo alegre» (1968), sobre las prácticas de la Policía Bonaerense; y fue popularizado luego del primer hecho de estas características producido después de la recuperación de la democracia, en el año 1987, conocido como "La masacre de Ingeniero Budge», que tomó estado público gracias al reclamos de familiares y organizaciones sociales. Recientemente, frente un caso cometido por un agente policial que asesinó por la espalda al jóven Juan Pablo Kukoc, después de un intento de robo, el actual Presidente de la Nación Mauricio Macri, junto a su Ministra de Seguridad Patricia Bullrich, recibió en la Casa de Gobierno al policía imputado y avaló su accionar, configurando un nuevo posicionamiento del Estado Argentino respecto de este tipo de hechos, por los que recibió sanciones internacionales: ya no el ocultamiento o la teoría de las «manzanas podridas», sino su legitimación. El apellido del policía homicida da nombre a esa nueva política de muerte, que se vulgarizó como «doctrina Chocobar».
} 
sujetos y relatos de la ley, señalando continuidades y definiendo respuestas en los textos escritos en la cárcel.

En una especie de manifiesto incluido en el noveno número de La Resistencia - la revista que publicamos en la Facultad de Filosofía y Letras con producción realizada en el Centro Universitario Devoto (CUD), dentro del Complejo Penitenciario Federal de la Ciudad Autónoma de Buenos Aires-, los participantes del taller en el que se edita escriben:

Somos dramas humanos, somos la muerte como protesta por la vida cegada, somos el empecinamiento en conservar la vida y el rechazo a la mentira del opresor, aunque nos quiebre la cabeza a garrotazos, aunque nos ahorque suicidándonos por el reclamo a las preguntas nunca contestadas (Actis Caporale et al., 2013: 2).

Pese a la corporalidad de la frase, esos «dramas humanos» se levantan y afirman en las palabras menos como un cuerpo que habla que como una fuerza, un «empecinamiento». A medida que avanza el texto, exponen y recuperan situaciones, volcando angustias, silencios, risas y solidaridades; insultan, usan el sarcasmo y se burlan de sí mismos y de los otros. Resistir en esas circunstancias, dicen, supone pasar «de un tema complicado a un chiste tonto con la simplicidad con la que solo un despojado, de autodestrucción ridícula, podría hacerlo» (3). Reconocen los límites de la denuncia, que «cae en saco roto», y sin embargo no callan, con la esperanza de ser escuchados, de llegar «a otros oídos», entrar «por otros ojos» (2). Esa voz, que se construye «en grupo», sin distinciones ni discriminación («No importa de qué país sos, si sos negro, rubio o coqueto. No interesa si sos cristiano o talibán»), interpela a los agentes penitenciarios, la policía, fiscales y jueces; y por supuesto, también a la sociedad que los instituye y avala como sistema. Sus aliados son otras personas en su misma situación y todo aquel que esté dispuesto a prestar el oído para escuchar.

En el mismo número de la revista, Gastón Brossio —ex estudiante de Letras en el centro universitario, ahora liberado; artista plástico y escritor-, empieza un texto breve titulado «Para nuestra sociedad insaciable», identificándose con desechos: «la mugre debajo de la alfombra, donde nos pisotean "las botas" y nadie dice nada, puesto que, en lo concreto, somos basura» (2013: 8). Habla de metáforas, mitos, medios y miedos, que construyen ángeles y demonios. Luego denuncia la situación del encierro penal («ii氵Señores, nos están matando en las cárceles!!!») y se pregunta si la solución es establecer la pena de muerte o seguir torturando «para que salgan con más rabia a la sociedad». El sujeto de la enunciación -o lo que queda de él一 se reduce a desecho, resto, y desde esa posición baja, hace un llamado, no para reclamar inclusión sino para dar voz a una demanda anterior de reconocimiento. No apela a la «tolerancia» o a un mayor nivel de inclusión social tanto como señala los límites de una democracia que hace una «asignación diferencial de la precariedad», es decir, expone a ciertas poblaciones a mayores niveles de riesgo, daño y violencia, al punto de reducir a los cuerpos a desechos y no considerarlos vidas que importan (Butler y Athanasious, 2017: 180-181; Butler, 2010: 20).

Al pie de la página, una ilustración de Jorge Navarro dibuja una especie de emblema con la figura de un dragón rodeado de motivos vegetales. Para pensar esta figura y continuar el análisis, quisiera citar a la otra revista que edita el mismo taller, aunque en un espacio diferente: el Centro Universitario 
Ezeiza del Complejo Penitenciario Federal I, ubicado en esa localidad de la Provincia de Buenos Aires. La revista se llama Los monstruos tienen miedo. La atribución de monstruosidad, en el título de la publicación, responde a una operación parecida a la que describe el texto de Brossio al hablar de demonios, y los sentidos condensados en la ilustración o emblema de Navarro. Remite a la vez a un antagonismo que puede leerse en los textos de presentación que encabezan casi todos los números de la revista, titulados: «¿Por qué “monstruos”?»7.

Si leemos la serie completa, vemos que el apelativo es asumido como uno de los modos en que el colectivo editor habla de sí mismo y de las personas que lo componen. Pero al mismo tiempo, en sentido contrario, es atribuido a los guardiacárceles, los periodistas, los funcionarios y el sistema en conjunto. No se trata simplemente de una inversión de la escena del juicio, sino de un movimiento que devuelve la palabra al que la empuña, hiere o justifica su condena (o golpes) con ella. Puedo resumir los avatares de la operación en algunos de esos textos.

En principio, el colectivo anónimo, o la firma que lo sustituye en algunos números, asume el lugar asignado, aunque denunciándolo como ficción: «somos una construcción metafórica y real de la deshumanización de los sujetos. Los monstruos existimos a partir del imaginario social que proyecta todo lo peor sobre nosotros, transformándonos, como se ve, en los culpables de todos los males sociales» (Fleita, 2014: 3). En el mismo texto, recuperan los elementos con los que se articula esa configuración:

Nuestro mayor delito es nuestro ADN, clásico prejuicio sobre el 'pibe chorro' (joven, pobre, morocho de viserita que ni estudia ni trabaja) a quien se lo estigmatiza y combate como a un enemigo peligroso venido del infierno. Se habla entonces de inseguridad, de mano dura, de aumento de penas, de bajar la imputabilidad de los menores; lo cual se traduce en el reclamo masivo de más policías, balas y represión. De lo que no se habla es de las causas, como la desigualdad y exclusión social, de la falta de trabajo y salario dignos, de que existe una justicia para pobres y otra para ricos.

El mismo problema aparece, levemente desplazado, en otro de esos textos de presentación, donde ya no se trata de desmontar las razones o destapar aquello que la ficción oculta, sino de pensar su productividad y potencia crítica:

El problema radica en que los monstruitos anden sueltos por ahí, recordándole constante e impúdicamente a la sociedad sobre todo lo que falta arreglar en materia social. Un ciudadano "honesto" no puede aceptar semejante atentado a la conciencia. Si hay miseria, que no se note, parece ser la consigna. Pero si nuestras acciones y omisiones generan más monstruosidad que las que puedan caber dentro de nuestros placares, ¿a dónde esconderlos para no vivir, si no con más seguridad, al menos con más comodidad ante nosotros mismos? (Serna, 2106: 1).

Los «monstruos» acá se vuelven testimonio de una sociedad excluyente; son el síntoma que señala la falta. «Desde acá adentro, no nos consideramos monstruos sino sobrevivientes de un sistema monstruoso» (Díaz, 2015: 1). Pero la insistencia en la palabra, la posibilidad de escribir, mantiene vivos los anhelos, esperanzas e ilusiones negadas afuera. E incluso la posibilidad de pensar una

\footnotetext{
${ }^{7}$ La pregunta puede leerse en varios sentidos en los textos: ¿por qué hablamos de monstruos? ¿Por qué nos llamamos o somos llamados «monstruos»? ¿Por qué la revista se llama Los monstruos...? ¿Por qué clase o tipo de monstruos es escrita o a cuáles responde?
} 
sociedad distinta: «queremos romper barreras y prejuicios haciendo visible lo que la cárcel invisibiliza: los monstruos no queremos ser más monstruos» (Fleita, 2014: 3).

En este punto, podríamos detenernos y releer los textos citados hasta ahora y preguntarnos, ¿qué ocurre cuando se da lugar a esas voces al margen del ley o en ese límite inferior del estado de derecho que es la cárcel? ¿Qué marcos tensan, corren o perturban? ¿Qué tipo de incomodidad genera al hablar —y ya no sólo ser hablado— el sujeto de la ley: el «monstruo», el «demonio», aquel sobre el que pesa la condena jurídica del sistema penal pero también la carga moral de toda una sociedad? Y también, por qué no, preguntarnos, ¿qué comparte ese sujeto o las textualidades a través de las cuales aparece o se expresa, con ese otro margen o resto que es la literatura?

Nicolás Rosa (1987: 11) decía que la literatura se afirma y funda en ese menos que la revela como «lo faltante del discurso social», borde o excrecencia del pleno lingüístico. En «Marginales en la noche», Jorge Panesi (2000: 339) explora las condiciones que llevan a la literatura a «buscar la ley en un fuera de la ley para hacer su propia ley que erige en los restos inasimilables, la basura cultural o los desechos». Esa posición, agrega, es la que le permite a la teoría literaria y a la literatura poner en escena el robo, el despojo, la desposesión, no como una lógica opuesta y alterna a la ley, sino como extensión de aquello mismo que la legalidad oculta y es parte de lo que siempre la hizo funcionar como ley:

El interior ilegal de la ley, la barbarización interna del nomos que se ve a sí misma como función apaciguadora y que se basa en la fuerza, en el arrebato, en el subsuelo de la desigualdad, en el despojo indiscriminado, en una forma delimitada y autoconfromada del robo que demarca todas las otras maneras del robo como fuera del círculo de la ley, como «fuera de la ley». (Panesi, 2000: 346-347).

Sabemos que la literatura como invención moderna se inscribe en las convenciones e instituciones que aseguran, en principio, el «derecho a decirlo todo» (Derrida, 1993: 16). Su destino está unido a la no-censura, al espacio público de libertad democrática. «No hay democracia sin literatura, y no hay literatura sin democracia». Pero, a la vez, consagrada a traspasar los límites, a descubrir de forma brutal o insidiosa los secretos y desplazar las reglas y los códigos, tiene que colocarse ella misma fuera de la ley, o al menos hacer recaer sobre ella la carga del escándalo, de la revuelta y la transgresión; ser más que cualquier otra forma de lenguaje, el «discurso de la infamia» (Foucault, 1996: 137).

En otro sentido, los «desarreglos del orden ficcional» propios de la relación entre literatura y democracia implican un modo de pensar «nuevas relaciones entre las palabras y las cosas, las percepciones y los actos, las repeticiones del pasado y las proyecciones del futuro, el sentido de lo real y lo posible, de lo necesario y de lo verosímil con el que se tejen las formas de experiencia social y de la subjetivación política» (Rancière, 2015: 14). De esa manera, podemos localizar la «política de la ficción», para leer los textos escritos en la cárcel no por lo que representan sino por lo que operan, es decir, las situaciones que construyen, las poblaciones que convocan, las relación de inclusión o exclusión que instituyen, reafirman o cuestionan, las fronteras que permiten trazar o borrar entre la percepción o la visibilidad y las posibilidades de acción. 


\section{El silencio cuenta más que las palabras}

«Es hora de levantar esta lengua / armada con hilos / arrancada a restos de voces», dice Nicolas Dorado (2010: 35) en «Años Caídos», un poema que forma parte del libro Ondas de Hiroshima, antología realizada en el taller de poesía del Centro Universitario San Martín (CUSAM), dentro de la Unidad 48 del Servicio Penitenciario Bonaerense. El libro es un objeto artesanal, pintado y cosido a mano en el taller de encuadernación del mismo centro universitario. No hay uno igual a otro. La tapa del que me tocó en suerte, de cartón corrugado, sin inscripciones, está salpicada con pintura de colores y tiene puntadas de hilo que enmarcan un título ausente. A uno y otro lado de la línea inferior de la costura que marca el recuadro sobre la tapa, hay un corte que la traspasa y llega hasta las primeras páginas, donde aparece sí el título.

La presentación refuerza el carácter singular, único e irrepetible, del libro-objeto de arte; y dice mucho sobre las condiciones en que fue producido. De hecho, las salpicaduras y el corte ocasional (probablemente accidental) en la tapa, son tanto un azar como el rastro de las condiciones y del cuerpo que la compuso; un acontecimiento fijado en el material que cruza tiempo y espacio en la «profundidad» (Didi-Hubermann 2015: 366-367) creada por la distancia o cercanía, la aceleración o el ralentamiento de las salpicaduras, la fuerza o presión diferencial aplicada a los cortes y el zurcido. Aparentemente inofensivo a la vista de los guardiacárceles que pueden verlo salir en las manos o el bolso de un docente o visitante ocasional (los libros, se dice, son «objetos peligrosos» en la cárcel), las salpicaduras, como manchas de sangre, hablan también de su contenido, al igual que el tajo y los puntos cosidos con hilos que remiten a otras heridas y cicatrices.

En otro poema de la antología, titulado «Cárcel», Waldemar Cubilla (2010: 29) escribe:

Anomalías vivientes
refuerzan el rito
impactan
$\quad$ perplejan
el brillo esgrime
el hilo tenso
que arranca y
lleva consigo la carne

El poema no parece hablar de lo que el título anticipa y, sin embargo, traduce, a través de metáforas, la experiencia del encierro y sus violencias. Como los hilos que enmarcan en la tapa la ausencia de palabras, sin decir muestra la violencia que grita desde el interior. Esos hilos, con los que se busca armar una lengua en el poema de Dorado y que, de hecho, cosen las páginas del libro, en el poema de Cubilla, arrancan la piel, repitiendo, denunciando, transformado en palabras, la acción, el corte o tajo del rito que marca el cuerpo. Como dice Mario Cruz (2012: 11) en el poema que pone nombre a la segunda antología producida en el mismo taller de poesía: «las cicatrices entienden dónde nacieron». Son huella y marca tanto de la violencia como de los modos de suturar la herida.

Cuando las palabras logran salir de la cárcel, cuando no se pierden en los papeles incautados o despedazados por la requisa, también se filtran, escapan y en cierto sentido cortan o rompen los marcos que habitualmente delimitan y contienen las miradas sobre el encierro penal (Butler, 2010: 27). Esas 
palabras son «incendiarias» tanto por lo que describen como por las condiciones en que fueron escritas y las restricciones impuestas a su circulación; y dejan una marca o signo que transporta la vida de un cuerpo y sobrevive para contarlo. En tal sentido, ofrecen un tipo diferente de respuesta; son «actos críticos de resistencia», que «viven a través de la violencia a la que se oponen» (Butler, 2010: 94). Y pese a las múltiples limitaciones que enfrentan, crean las condiciones para fomentar un llamamiento a la justicia y al fin de la violencia. Porque como dice Wk o Waikiki (pseudónimo de Gastón Brossio ${ }^{8}$ ) en uno de los poemas de su libro 79. El ladrón que escribe poesía: «la astucia de la lapicera se encuentra en la tinta. / Que deja marcas como los recuerdos de la guerra, / Con los ojos llenos de muerte, pero de vida también» (2015: 94)

El valor crítico de la escritura en la cárcel no reside exclusivamente en las cosas que dice, muestra o deja ver, sino también en aquello que no dice o calla pero contiene sobre el proceso que le dio lugar: las palabras y acciones que resiste y a las que a veces contesta, así como el recorrido que va de la escritura en birome sobre un cuaderno de hojas ralladas o un papel cualquiera a la edición impresa. Porque para llegar a ser libro o revista, la escritura tiene que superar múltiples barreras físicas y simbólicas; trabas, prohibiciones, dificultades, prejuicios, silencios, censuras. A veces, «el silencio cuenta más que la palabras» (Cabrera et al., 2015: 18). Las huellas del acto en el producto señalan así tanto a la subjetividad que escribe, su tema o historia, como a las instituciones que la mantienen encerrada y el tipo de organización social que las funda, avala y sostiene. La lengua, «arrancada a restos de voces» en la poesía, podría dar cuenta, tal vez, de los cismas o fisuras de la legalidad o la moral de la ley que enmarca los discursos dominantes sobre el castigo, produciendo una disonancia en el concierto de voces que convoca a la «mano dura» y la represión.

$\mathrm{Si}$, como sostiene Jaques Derrida (1997: 33, 47-48), la legalidad es una fuerza no fundamentada que se basa en una creencia e instaura una convención, apoyándose en la repetición de una serie de consignas o enunciados previos, no está exenta del momento crítico que abre el intervalo o espaciamiento en la escritura, su desplazamiento y posible cuestionamiento y hasta su transformación. Cuando se produce en circunstancias extremas o encarna voces en los márgenes de la ley, la escritura abre un espacio de experimentación con la palabra que interpela performativamente tanto las identidades asignadas y los lugares establecidos como las normas y regulaciones que las configuran, despliegan y hacen legibles. La acción que pone en escena y lleva adelante la literatura tiene la potencialidad de dejar marcas sobre las lenguas y tramas que atraviesan el encierro, afectando y produciendo nuevas condiciones de posibilidad. Desde un lugar marginal o menor, puede ayudar a resaltar las contradicciones, poner en crisis o al menos perturbar las bases ideológicas y principios

\footnotetext{
${ }^{8}$ Como Brossio, que explicita la construcción de esa especie de alter ego en el prólogo de su primer libro, titulado con ironía «Prontuario» (Wk, 2015: 7-9), muchas veces los/as autores/as en contextos de encierro apelan a apodos o pseudónimos, no para esconder su identidad tanto como para dar margen de acción a las palabras. Las máscaras, las identidades sesgadas y los nombres colectivos, como «Pensadores Villeros Contemporáneos» $\mathrm{O}$ «PV», la otra firma en la que se identifica Brossio desde la tapa de su libro, pueden ser también una respuesta al lenguaje injurioso o una estrategia para enfrentar el aislamiento y la lógica despersonalizada del llamado tratamiento penitenciario.
} 
morales sobre los que descansan las interpretaciones hegemónicas sobre la ley y el delito, cuestionando o al menos resistiendo el poder y la obediencia a la autoridad.

La cárcel es un espacio saturado de escritura e imágenes; no sólo las que proliferan en legajos penitenciarios y archivos judiciales o en los tratados de derecho penal y criminología, sino también las que producen y ponen en circulación los medios y las industrias culturales. Pero hay un punto de vista que, en general, no aparece en esas textualidades y representaciones: el del «otro lado de la reja», el que configuran las voces y palabras de sus principales protagonistas, las personas encarceladas (Parchuc, 2015: 24; Daroqui et al., 2006: 18; Davis, 2003: 15-18). Esas voces están ausentes del debate público y las discusiones especializadas que involucran directamente a los cuerpos que las portan. Son voces desechadas, censuradas, silenciadas y, por ende, proscritas. Podríamos preguntarnos sobre los efectos de esa ausencia y las implicancias de tal restricción para el orden democrático (Jacobi, 2008: 82) y, al mismo tiempo, sobre las posibilidades que abre o permite contrarrestar la edición, publicación y puesta en circulación de esas voces y palabras.

La producción de la subjetividad se realiza «no sólo por medio de la regulación del habla, sino por la delimitación del ámbito social del discurso enunciable» (Butler, 2004: 219-220). Por lo tanto, la cuestión no es sólo lo que cada uno/a puede decir, sino cómo se recorta el plano de lo decible y el ámbito dentro del cual alguien puede empezar a hablar. La censura no sólo opera vedando ciertas expresiones sino a través de la definición de «quién será sujeto dependiendo de si el habla de ese candidato a la subjetividad cumple determinadas normas que regulan lo que se puede decir y lo que no» (220). Al mismo tiempo, si esa persona no está habilitada a hablar o aparece sobre ella un manto de censura previa, el espacio de la enunciación se recorta y cierra. Las escenas o situaciones en las que las personas privadas de libertad hablan producen un borde simbólico en el campo de lo enunciable, que pone en juego el margen o límite de lo que se dice o cuenta, pero también interpela nuestra capacidad de oír y nuestra disposición a escuchar; y, por lo tanto, la posibilidad de dar carta de ciudadanía o el mínimo de reconocimiento necesario para que esas subjetividades hablen.

Si la literatura es un espacio abierto al silencio y la ausencia, hasta la privación del habla puede volverse potencia en la escritura, siempre que haya un resto de voz que sepa «enhebrar el silencio» para «contar algo que no está siendo contado» (Abrach - Charaf - García, 2016: 7, 9). En uno de los poemas de la antología de jóvenes escritores en contextos de encierro que editamos con el título Expresos literarios, Luis articula en palabras el espacio ocupado por el silencio, y busca que lo escuchen, «usando eso, un simple silencio»:

Un gran vacío lleno de nada un gran espacio ocupado por el silencio silencios, diciendo miles de cosas, pero expresando solamente, nada más que solo silencios, absurdos silencios, cansancio de escuchar y sin oír una sola "p" palabra gritando en silencio voy, diciendo todo lo que siento, expresando todo, con una simple expresión, 
el silencio,

buscando que todos me escuchen con tan solo usando eso, un simple silencio (Abrach - Charaf - García, 2016: 65).

La insistencia en el silencio y la soledad («solo», «solamente», «sola») se vuelve «cansancio de escuchar» sin oír «una sola "p" palabra»" ${ }^{9}$, pero también es la condición para esa fuerza que se expresa «con una simple expresión», a través de «un simple silencio». La simpleza señala una posición enunciativa: no puede imponerse sobre ese «gran vacío», ocupado por el silencio; se sume en esa situación para hacer brotar palabras desde el silencio de la escritura.

En un sentido similar, Julián Galeano (2012: 16) rescata otra inflexión posible de esa voz que dice en silencio en Las puertas salvajes:

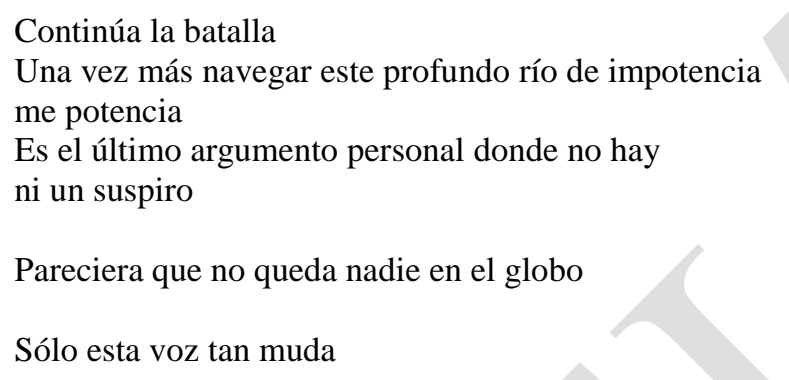

Es que está tan frío el corazón

Como en el poema de Luis, la potencia de la palabra se afirma en la ausencia y la negación; en el lugar donde «no hay ni un suspiro», donde se enfría el corazón y pareciera que «no queda nadie». La mudez de la voz acallada habla del encierro carcelario y el silenciamiento, pero también de la capacidad de decir más allá de o desde ese silencio, con la palabra escrita que, como la literatura, «hace hablar a la vida» de una manera «a la vez más muda y más parlante que la palabra democrática» (Rancière, 2011: 31). Esa palabra escrita sobre el cuerpo del lenguaje, que nadie profiere, que no responde a la voluntad de significar ni expresar la verdad, sin embargo, la dice; y con ese gesto se opone a la charlatanería y la mentira, teniendo en cuenta, o mejor, haciendo contar a los que «no cuentan» (31-32, 67-68).

\section{La lengua del odio}

El odio y la crueldad son afectos políticos fundamentales en el neoliberalismo. La ruptura de los lazos sociales resulta indispensable para imponer las políticas económicas de miseria planificada y exclusión. El ataque a los modos de organización de base y la desintegración de los vínculos afectivos y de solidaridad producto del shock generado por la situación económica y el miedo a la violencia represiva, ejercida como terrorismo de estado o en su forma legalizada, es producido o reforzado por un proceso de transformación moral articulado a través de lenguas o retóricas de odio que normalizan e incluso vuelven «natural» la segregación, mientras producen hábito o acostumbramiento al

\footnotetext{
${ }^{9}$ La letra $p$ puede ser reticencia o estar simplemente remarcando la materialidad y sonoridad de la palabra escrita.
} 
sufrimiento y el dolor. La moral de la ley construye y se apoya en matrices ideológicas y regulaciones que deshistorizan, descontextualizan y en ocasiones incluso «biologizan» la relación entre desigualdad y diferencia, convirtiendo atributos o condiciones impuestas en códigos de lectura de los cuerpos que aparecen tramados por el racismo, la xenofobia y otras formas de discriminación (Segato, 2007: 149152; Delfino, 1998: 40-41).

En su funcionamiento, esta moral no constituye un conjunto estable de operaciones, sino que implica un trabajo ideológico de producción de consensos y marcos de inteligibilidad, que suponen regulaciones cognitivas pero también de afectos y sensibilidades, y apuntan a la subjetividad como soporte de la autoridad y el dominio político (Butler, 2010: 67-69; Delfino - Parchuc - Rapisardi, 2007: 99). La cárcel tiene una función central dentro de esas regulaciones como «un maquinaria productora de sufrimiento, dolor, subordinación», pero también «de delincuencia material y simbólica al "servicio" de un orden social» (Daroqui, 2008: 13). El secuestro institucional se ha vuelto «una estrategia de gobernabilidad del conflicto y el malestar social emergentes de las relaciones de explotación y desigualdad constitutivas del capitalismo», amplificadas en su etapa neoliberal. La cárcel produce delincuencia, como decía Foucault (1991: 22-23), y saca provecho de esa productividad tanto en las economías legales e ilegal como en el orden cultural y político.

Si prestamos atención a la lengua que articula esa moral, podemos observar los enunciados que produce y el modo en que recorta el espacio de lo enunciable y aprehensible, justificando o habilitando distintas formas de violencia. En especial, me interesa prestar atención sobre todo a cómo un susurro o rumor social asociado al desprecio y la crueldad se está volviendo, lenta pero insistentemente, lengua común; ya no se recluye en el espacio privado, sino que avanza y exige ser escuchada en arena pública. En un trabajo publicado recientemente, Gabriel Giorgi (2018) lee los Diarios del odio ${ }^{10}$ para caracterizar ese agenciamiento que se despliega como una lengua anónima y compartida en los comentarios de lectores en medios on line y las redes sociales, trazando «una línea de disputa en el espacio público sobre lo decible en contexto democrático, excavando el espacio para nuevas enunciaciones que, a contrapelo de lo que consideran corrección política, reclaman su derecho a la expresión a partir del desarmado de pactos previos: una guerra en y por la lengua». Esos pactos, en nuestro país, están atados a la lucha contra la dictadura y el proceso de recuperación democrática, encabezada por los organismos de derechos humanos.

La reacción frente a la ampliación progresiva de derechos y el reconocimiento de nuevos sujetos y problemáticas durante los gobiernos populares de la década pasada, se erige ahora como un intento de socavar las base de sustentación de la construcción política que los hizo posibles; las pactos sobre los que se fundaron, las alianzas o redes que fueron tejiendo y las nuevas poblaciones o colectivos que permitieron reconocer y articular: «¿Dónde están los derechos humanos para las víctimas de la inseguridad?», «Estoy harto de los derechos humanos». Estos enunciados se complementan con otros

\footnotetext{
${ }^{10}$ La instalación montada en el año 2014 por Roberto Jacoby y Syd Krochmalny, que recopila comentarios on line de los diarios de mayor tirada en el país: La Nación y Clarín, que fue pasada luego a soporte libro y continuada en la puesta musical y coreográfica de Silvio Lang con el grupo ORGIE.
} 
de resonancia más extendida y duradera: «Son delincuentes y van a morir delincuentes», «No tienen recuperación», «Que se pudran en la cárcel», «Hay que matarlos a todos». No sólo se repiten en internet sino que se escuchan cada vez más como argumentos con pretensión de legitimidad, que intentan correr los límites de lo enunciable en la esfera pública, alterando los marcos legales y de sentido de la democracia.

Podríamos preguntarnos, ¿cómo tematizan y responden los textos escritos en la cárcel a ese estado de la lengua? ¿Qué posición asumen frente a esa moral de la ley y la lengua del odio que permea o contamina enunciados, afectos y sensibilidades? ¿Cuáles podrían ser las armas para enfrentar esos enunciados y retóricas de odio que habilitan formas de anulación e incluso destrucción del otro que representan? ¿Qué estrategias de resistencia, torsiones e inversiones encontramos en los relatos y experiencias del encierro carcelario?

\section{Camino por el borde}

Como vimos hasta ahora, las respuestas que articulan los textos escritos en la cárcel ante los dispositivos que los encierran y condenan, no consiste en la afirmación de una posición contraria o la asunción de una conciencia o subjetividad fuertes, tanto como en una práctica silenciosa de resistencia al poder que establece la ley. En el primer poema de su libro Bancáme y punto (2013), Liliana Cabrera - escritora, docente e integrante de la asociación civil y cooperativa de trabajo Yo No Fui- nos enseña una de las formas de esta estrategia:

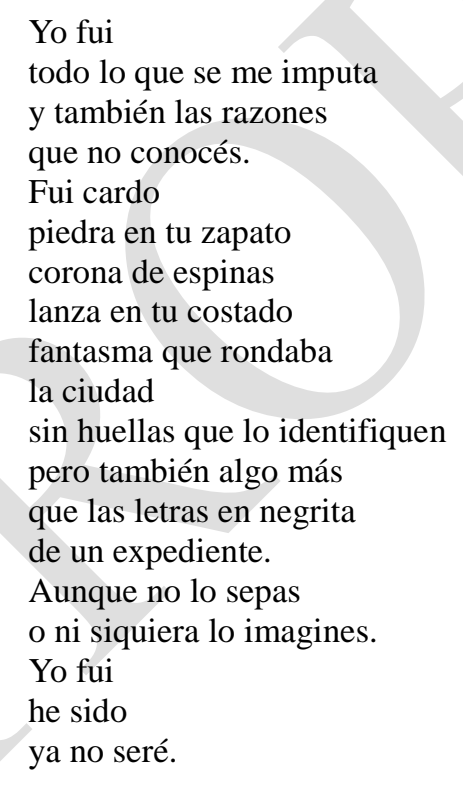

En esas pocas líneas reconstruye fragmentos de vida desde los restos que la condena moral y los discursos de la ley no pueden capturar. Recurre a imágenes religiosas y literarias, usa palabras del lenguaje judicial para hablar de sí e interpela, a través de esos discursos e instituciones, la palabra del otro que los encarna y, con ella, juzga. No niega la imputación, sino que reescribe la condena; y coloca al que la ejerce en el lugar del desconocimiento («las razones que no conocés») y el no saber («Aunque 
no lo sepas o ni siquiera lo imagines»), con las armas de una justicia distinta de la del hombre y la divina, que tematiza el poema.

En «Las tretas de débil», Josefina Ludmer, leyendo a Sor Juana Inés de la Cruz, reconstruye la táctica que consiste en cambiar, desde el lugar asignado y aceptado, «no sólo el sentido de ese lugar sino el sentido mismo de lo que se instaura en él» (1984: 53). De una manera similar a la operación que describe Ludmer para caracterizar esa «treta», Cabrera separa también, al escribir, el campo del decir, fundado en la ley y la palabra del otro, del espacio del saber que se apoya y construye en la intimidad de la escritura. Y así combina, como toda táctica de resistencia, «sumisión y aceptación del lugar asignado por el otro, con antagonismo y enfrentamiento, retiro de colaboración» (51-52). En el medio se produce un cambio de posición subjetiva plasmado en la enunciación. En el pasaje que va de la primera frase («Yo fui») a la última («ya no seré»), el poema introduce la negación como proyección hacia el futuro, para imaginar la posibilidad de reinventarse en la escritura que repasa, vuelve a marcar y afirma ser «algo más que las letras en negrita de un expediente».

Encuentro otra versión de la misma astucia en el poema de Wk «De cabeza». Cito un fragmento:

De cabeza me tiro al racismo,
Porque el odio hacia nosotros
Lo genera el noticiero.
Por eso, no me importaría
Inmolarme como un talibán
Frente a todo este conductismo social.
De cabeza me tiro a la parca.
Y si me quieren cortar la cabeza,
No tengan miedo, yo se las doy.
Sin oponer resistencia, ni clemencia,
Porque tengo en cuenta
Que no es la cura a su demencia (Wk, 2015: 30).

El gesto de tirarse «de cabeza», que en el uso habitual del término tiene un dejo de arrojo y valentía, en el poema convive con una suerte de resignación ante esa entrega sacrificial. Y, sin embargo, no puede leerse como sumisión; se encara más bien, sin vacilar, con el tono de un desafío. Por otro lado, no sólo coloca, como Cabrera, a quienes emiten juicios y condenan en la posición del no saber y el desconocimiento, sino que proyecta sobre ellos la «demencia» de quien odia y mata, dando vuelta la escena y los atributos que se le imputan. De esta manera, devuelve el odio transformado en poesía, como en «Tus palos» («Tus palos / Pasaron a ser el alimento de mi pluma...»), o bien, escribe «Con odio», descargando bronca, ira y rabia, contra «toda la maldita historia» de sufrimiento, muerte y dolor, amenazando y prometiendo la muerte «con más odio / para ser justo» (Wk, 2015: 25, 113). Como en Cabrera, hay un ejercicio literario de justicia que no puede leerse desde los códigos de la ley y las normas establecidas.

En su primer libro: La venganza del cordero atado, Camilo Blajaquis (pseudónimo de César González) le pone nombre a ese sujeto indefinido al que dirige su odio el poema de Wk: reúne en el relato de un sueño de justicia a oficiales, magistrados, abogados, fiscales, senadores, diputados, 
ministros, presidentes, periodistas, jefes y patrones, vestidos con «sus trajes con botones repletos de avaricia y con el más enfermo desprecio calzando sus pies» (2010: 62). Los encierra en su imaginación, para que escuchen su discurso y sean sometidos a su voluntad; para que paguen con sufrimiento «por causar tanto hambre durante tantos siglos [...] por haber infectado el aire del mundo de tanto odio y egoísmo». Pero el narrador del relato decide darles una segunda oportunidad («la que ustedes no dieron nunca») y los invita a «besarle los pies a la vida» y después aceptar la muerte como «la única manera de aliviar el dolor que causó su vicio de masacrar corazones y pisar cabezas sin asco para escalar en su montaña de categorías». Luego los coloca frente a la «tropa de olvidados, marginados, excluidos, locos y presos»y ordena que los maten (63).

Me interesa del relato de Blajaquis no su argumento, sino la inflexión de la lengua con la que coloca en su lugar a los personajes que nombra. En la escena de juicio que produce el texto no hay cómputo de penas, castigos ejemplares ni separación moral entre «buenos» y «malos». El uso de la ironía y el sarcasmo le permite mantener a raya los preceptos morales que contaminan los discursos por derecha y por izquierda. Esa moral que, como declara en un poema incluido en Crónicas de una libertad condicional, «sigue gobernando nuestra sociedad / desde el movimiento y los reposos / hasta las causas y los efectos / desde el plano urbano hasta la superficie campesina».

En la entrevista que le hacen sus compañeros del Colectivo ¿Todo Piola? que aparece como epílogo de su segundo libro, César González contradice algunas de las modalidades de la acción institucional o comunitaria en la cárcel y los barrios, señalando no sólo la tortura y la represión, sino las posiciones de quienes «tienen un discurso progresista pero se les nota la moral anti-chorro» (Blajaquis, 2011: 169). Su advertencia permite recortar las posiciones de quienes establecen una relación moral con el otro, para «corregirlo», los que hablan de «recuperación» y «transmiten docilidad» (174).

A partir de su experiencia como editor de la revista ¿Todo Piola? y como docente de talleres de escritura en el barrio Carlos Gardel de Morón, refiere otro modo de posicionarse en su trabajo que no moraliza la relación con los sujetos ni los territorios. Podemos leer ese posicionamiento en dos escenas. La primera, cuenta cómo se acerca y pone a prueba la revista entre los jóvenes del barrio:

El día que sacamos el número 5 de la ¿Todo Piola? fui y se la llevé a los guachos. Ese día me dije: de lo que pase acá depende lo que viene. [...] Si me rechazaban la revista y me comía un bolaceo estaba en el horno. Iba a tener que remarla. Yo quería caminar por el barrio, no me gustaba estar guardado. Lo que pasó ese día fue algo surrealista, algo cinematográfico.

Había como veinte pibes, una noche que hacía calorcito, aunque ya era mayo. Me acuerdo que estoy llegando y aparece uno por la esquina tirando al aire: ¡pum! ¡pum! ¡pum! ipum! Y sale otro, “ibuena guacho!”, ¡pum! ¡pum! Yo llegué y a la primero me la tenía guardada. Hasta que en un momento les dije: : "che muchachos les quiero mostrar algo que estoy haciendo con otra gente". Saco dos, las muestro, y se las doy a dos pibes con los que más afinidad tengo. "Uh, el barrio, mirá vo las fotos", que pum que pam. Y veo que uno está parado, la hojea, la hojea, y como que frena en un texto, no sé cuál, se va unos pasos donde hay una escalera, se sienta... A todo esto yo me hacía el que no miraba, ¿viste? ¡Y se cuelga a mirarlas! Y viene otro más y dice, “uuh, qué es esto?”. "Nada , una revista”. “Uy, ¿tené?”. "Más vale, tomá”. Entregué como diez. Pim, pum, pam, se empezaron a enganchar todos. Y les dije: "por favor, chicos, no la rompan". Y lo loco es que después anduve por un par de casas de los pibes, iy la tenían en el modular! A veces dicen que es la revista del barrio, aunque saben que escribe otra gente, que $¿$ Todo piola? está por todos lados, pero ellos creen que es el barrio, y está buenísimo que sientan eso (Blajaquis, 2011: 171-172). 
El desplazamiento del «ipum! ;pum! ¡pum! ¡pum!» de los disparos al aire al «pim, pum, pam» de la lectura y la conversación, condensa los sentidos de la escena: el reposicionamiento de los cuerpos que se apartan para leer, al lado de una escalera, la transformación subjetiva que implica reconocer el barrio en las imágenes y la palabra escrita, de una manera distinta a la que aparece en la prensa y los noticieros. Podemos notar también como el sujeto narrativo se corre del centro, entrega las revistas, no dirige la lectura y simplemente ve lo que pasa.

La segunda escena transcurre en el taller y tiene como preámbulo una reflexión sobre dichos y posturas:

En el barrio hay cierta gente que está en la política y me odia. Se la pasan hablando mal de mí. Es lo que me pasó en la cárcel con algunos militantes supuestamente de izquierda. Yo solo pedía que me dejen ser. "No, así no es, César, así no es”, me decían. Pero pará, si no estoy haciendo algo violento, ¡no me cortes el mambo! (174).

Más adelante, refiriendo cómo esas posiciones se reproducen en el barrio y cómo trata de manejarse, de manera distinta, en su taller, dice:

Yo lo manejo de otra manera, voy aprendiendo. Y desde un primer momento se los dejé bien claro a los pibes del taller: yo no soy profesor, no me interesa lo que hagan en la semana, el que se droga, el que anda choreando, mientras vengan al taller y escriban. Tuve momentos chivos. Una vez vino un pibe enfierrado. Si se le escapaba un tiro iba a ser terrible. No lo eché ni a palos al guacho. “Está en seguro?”, le dije. "Sí, sí", "Bueno, dejala en seguro y no la saques acá adentro". "No, está bien", y se quedó ahí escuchando (175).

Con estos gestos y posicionamiento, González politiza el vínculo a través de «herramientas de distinción ética y no represión», reescribiendo la relación de los cuerpos con los modos de subjetivación del poder y las coacciones de la autoridad moral: «lo que hago es arte no política. Aunque en realidad eso es un juego, porque el arte en sí mismo es político» (178).

La literatura permite recorrer el borde donde el lenguaje recupera los restos o desechos y se estira para incluir otras experiencias y realidades. La escritura en la cárcel recupera del silencio las voces acalladas, abre espacios de la enunciación y pone palabras a otras formas de mirar y decir. En ese recorrido, produce alianzas, gana terreno y borda de otra manera las tramas que tejen nuestro presente y el futuro. Un poema o un relato no sólo ponen en circulación palabras, habilitan y dan lugar a otras voces y subjetividades, sino que pueden convertirse en un poderosos catalizadores de estrategias y acciones contra la violencia y los dispositivos de la ley. Crean otros espacios, ritmos y temporalidades, que pueden «trazar pliegues y grietas en la opacidad de la vida, dentro y fuera del encierro; construir nuevos escenarios sensibles, [...] reordenar y redistribuir roles, historias, lugares y tiempos» (Rodríguez, 2016: 13). Escapar, aunque sea momentáneamente, de las «redes del poder» (Foucault, 1991), para imaginar otra forma de vivir y estar con otros. Como en el poema de Susana Ciri, incluído en la antología poética de Yo No Fui:

Camino por el borde de tu barco de trapitos y hacemos equilibrio 
Todos los materiales citados en estas páginas parten de experiencias de contacto con la literatura que se transformaron en otra cosa: un poema escrito en un taller que funda una pequeña editorial; la lectura de una novela en una celda de castigo que inaugura un proyecto artístico y literario; un taller de poesía que crece y se transforma en una cooperativa de trabajo que aloja a mujeres liberadas; una conversación sobre libros que construye un puente hacia afuera, imagina y termina construyendo una biblioteca popular y un centro comunitario; un taller de escritura que se convierte en un programa universitario de intervención educativa y cultural en contextos de encierro. No importan aquí tanto las referencias y asociaciones como preguntarnos qué es lo que posee (o «desposee») y hace la literatura para producir ese «encuentro» (Panesi 2009); qué nuevos horizontes y posibilidades proyecta; qué espacios abre o permite imaginar.

\section{Referencias bibliográficas}

ABrach, L. - ChARAF, S. - GARCíA, Y., comps. (2016): Expresos literarios. Antología de jóvenes escritores en contextos de encierro. Buenos Aires, Universidad de Buenos Aires.

ACTIS CAPORAlE, J. et al. (2013): «¿Quiénes somos? La Resistencia somos todos», La Resistencia, 9, pp. 2-3.

Blajaquis, C. (2011): Crónica de una libertad condicional. Buenos Aires, Tinta Limón. (2010): La venganza del cordero atado. Buenos Aires, Continente.

Brossio, G. (2013): «Para nuestra sociedad insaciable, La Resistencia somos todos», La Resistencia, 9 , p. 8.

ButLer, J. (2004): Lenguaje, poder e identidad. Madrid, Síntesis. (2010): Marcos de guerra. Las vidas lloradas. Buenos Aires, Paidós.

Butler, J. - Athanasious, A. (2017): Desposesión: lo performático en lo político. Buenos Aires, Eterna Cadencia.

CABRERA, L. (2013): Bancáme y punto. Buenos Aires, Bancáme y punto.

CABrerA, L. et al. (2015): Iluminaciones. Fotografía en la cárcel de mujeres. Buenos Aires, Asociación Civil Yo No Fui / Centro Cultural Haroldo Conti.

CAIMARI, L. (2017): La vida en el archivo. Goces, tedios y desvíos en el oficio de la historia. Buenos Aires, Siglo Veintiuno.

- (2014): Apenas un delincuente. Buenos Aires, Siglo Veintiuno.

Cesaroni, C. (2003): Masacre en el Pabellón Séptimo. Temperley, Tren en Movimiento - Cooperativa Esquina Libertad.

Ciri, S. (2006): «Sin título», en A. Rosselet et al., Yo No Fui. Antología poética. Buenos Aires, Voy a Salir y si me Parte un Rayo. 
Cubilla, W. (2010): «Cárcel», en I. Albornoz et al., Ondas de Hiroshima. Antología poética. Buenos Aires, Centro Universitario Azucena Villaflor - Asociación Civil Va de Vuelta Universidad Nacional de San Martín, p. 29.

Cruz, M. (2012): «Puertas salvajes», en P. Tolosa et al., Puertas salvajes. La Plata, La Fraternidad, p. 11.

DAROQUI, A. (2008): «Neoliberalismo y encarcelamiento masivo en el siglo XXI. De la resocialización a la neutralización e incapacitación», Encrucijadas, 43, pp. 12-16.

Davis, Y. A. (2003): Are Prisons Obsolet? Nueva York, Seven Stories.

DELFINO, S. (1998): «Desigualdad y diferencia: retóricas de la identidad en la crítica de la cultura», Doxa, 18 , pp. 28-44.

DELFINO, S. - PARCHUC. J. P. - RAPISARDI, F. (2007): «Las acciones contra la discriminación y la represión desde la carrera de Letras», Espacios de Crítica y Producción, 36, pp. 97-111.

DERridA, J. (1993): «La ofrenda oblicua», en Passions. Trad. Jorge Panesi. Paris, Galilée.

Didi-Huberman, G. (2017): «Introducción», en Sublevaciones. Saenz Peña, Universidad Nacional de Tres de Febrero.

(2015): Ante el tiempo. Buenos Aires, Adriana Hidalgo.

DíAz, C. S. (2015): «¿Por qué “monstruos”?», Los Monstruos Tienen Miedo, 5, p. 1.

Dorado, N. (2010): «Años Caídos», en I. Albornoz et al., Ondas de Hiroshima. Antología poética.

Buenos Aires, Centro Universitario Azucena Villaflor - Asociación Civil Va de Vuelta Universidad Nacional de San Martín, p. 35.

FleitA, E. (2014): «¿Por qué “monstruos”?», Los Monstruos Tienen Miedo, 3, p. 3.

Foucault, M. (1991): Las redes del poder. Buenos Aires, Almagesto. (1996): La vida de los hombres infames. La Plata, Altamira.

Galeano, J. (2012): «Sin título», en P. TolosA et al., Puertas salvajes. La Plata, La Fraternidad, p. 16.

GiORGI, G. (2018): «La literatura y el odio. Escrituras públicas y guerras de subjetividad», Transas. Letras y Artes en América Latina, en http://www.revistatransas.com/2018/03/29/1a-literatura-yel-odio-escrituras-publicas-y-guerras-de-subjetividad/ (última consulta: 30-5-2018)

Hall, S. - Critcher, C. - JefFerson, T. - Clarke, J. - Roberts, B. (1978): Policing the Crisis. Mugging, the State and Law and Order. London, Macmillan.

JACOBI, T. (2008): «Slipping Pages through Razor Wire: Literacy Action Projects in Jail», Community Literacy Journal, 2, pp. 67-86.

LUDMER, J. (1984): «Las tretas de débil», en E. ORTEGA y P. GONZÁLEZ, eds. La sartén por el mango. Puerto Rico, Huracán, pp. 47-54.

PANESI, J. (2000): «Marginales en la noche», en Críticas. Buenos Aires, Norma.

- (2009): «Los chicos imposibles», portal.educ.ar, en http://portal.educ.ar/debates/contratapa/ recomendados-educar/donde-esta-el-nino-que-yo-fui.php (última consulta: 30-5-2018). 
PARCHUC, J. P. (2015): «La Universidad en la cárcel: teoría, debates, acciones», Redes. Revista de Extensión, 1, pp. 18-36, en: http://revistascientificas.filo.uba.ar/index.php/redes/article/view/ 1463 (última consulta, 25-5-2018).

(2013): «Escribir en la cárcel: acciones, marcos, políticas», Boletín de la Biblioteca del Congreso de la Nación, 128, pp. 67-81.

RANCIÈRE, J. (2015): El hilo perdido. Ensayos sobre la ficción moderna. Buenos Aires, Manantial. (2011): Políticas de la literatura. Buenos Aires, Libros del Zorzal.

RodrígueZ, A. (2016): «El arte como política de libertad», Yo Soy, 1.

RosA, N. (1987): «Estos textos, estos restos», en Los fulgores del simulacro. Santa Fe, Universidad Nacional del Litoral, pp. 9-18.

Segato, R. (2007): «El color de la cárcel en América Latina. Apuntes sobre la colonialidad de la justicia en un continente en desconstrucción», Nueva Sociedad, 208, pp. 142-161.

SERNA, L. (2016): «¿Por qué los monstruos?», Los Monstruos Tienen Miedo, 7, p. 1.

WALSH, R. (1968): «La secta del gatillo alegre», CGT. Órgano oficial de la Confederación General del Trabajo, 2, p. 4.

WaCQuAnt, L. (2004): Las cárceles de la miseria. Buenos Aires, Manantial.

ZAFFARONI, R. E. (2006): El enemigo en el derecho penal. Buenos Aires, Ediar. 